\title{
Perinatal high methyl donor alters gene expression in IGF system in male offspring without altering DNA methylation
}

\begin{abstract}
Aim: To investigate the effect of a protein restriction and a supplementation with methyl donor nutrients during fetal and early postnatal life on the expression and epigenetic state of imprinted genes from the IGF system. Materials \& methods: Pregnant female rats were fed a protein-restricted diet supplemented or not with methyl donor. Results: Gene expression of the Igf2, H19, Igf1, Igf2r and Plagl1 genes in the liver of male offspring at birth and weaning was strongly influenced by maternal diet. Whereas the methylation profiles of the Igf2, H19 and Igf2r genes were remarkably stable, DNA methylation of Plag/1 promoter was slightly modified. Conclusion: DNA methylation of most, but not all, imprinted gene regulatory regions was resistant to methyl group nutritional supply.

Lay abstract: Fetal environment influences fetal growth and may confer a risk to develop metabolic diseases, possibly through alterations in the epigenetic state of the genome. Imprinted genes constitute a special class of genes that are crucial for the control of fetal and postnatal growth and are closely associated with energy metabolism. In addition, these genes are finely regulated by epigenetic mechanisms that are themselves influenced by environmental factors. This study showed that methyl donor nutrients in maternal diet strongly influenced the expression level of imprinted genes in the liver of rat offspring, despite a mild effect on epigenetic regulation.
\end{abstract}

First draft submitted: 14 October 2016; Accepted for publication: 15 November 2016; Published online: 13 December 2016

Keywords: DNA methylation $\bullet$ early growth $\bullet$ imprinted genes $\bullet$ methyl donors $\bullet$ nutritional programming $\bullet$ protein restriction

The concept of 'nutritional programming', initially based on observations on undernourished human populations [1-3] and cases of utero-placental deficiencies $[4,5]$, suggests a link between fetal growth restriction and metabolic outcomes [6-9]. Animal models have been widely used to demonstrate that maternal nutrition can influence the epigenetic state of the fetal genome. This may constitute a major molecular mechanism linking early nutrition and altered gene expression and predispose to specific metabolic diseases later in life (for review [10-13]). Protein restriction is shown to be associated with altered methylation at a large number of genomic loci [14] or at specific promoters [15-21] and nutritional supplementation with one or several methyl donors (MDs) have been used to reverse the effects of protein restriction and were indeed shown to influence methylation profiles at specific loci (review in [22]). MD nutrients contribute to the one-carbon/MD pathway, critical for its role as provider of methyl groups for methylation reactions, including DNA methylation. Folic acid, methionine and choline are the main methyl group donors in most cell types, whereas betaine is used as an alternative MD in liver
Valérie Amarger*,1, Fanny Giudicelli', Anthony Pagniez ${ }^{1}$ \& Patricia Parnet ${ }^{1}$ 'UMR PHAN, INRA, Université de Nantes, 44000 Nantes, France *Author for correspondence: Tel.: +33253482008 Fax: +33253482003 valerie.amarger@univ-nantes.fr

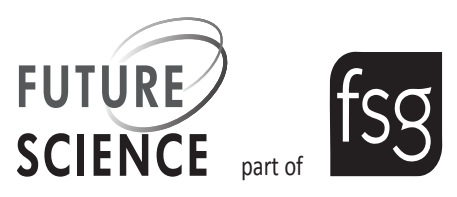


and kidney mostly [23,24]. The MD pathway relies on the activity of several enzymes that require additional cofactors, including vitamin B12 and zinc.

In humans, it is widely acknowledged that MD nutrients influence pregnancy outcomes and fetal health [25-27], and women who wish to be pregnant are currently advised to consume high amounts of $\mathrm{MD}$, including folic acid. In addition, several countries have adopted a systematic fortification of basic food with folic acid and this policy has proven its efficiency for the reduction of birth defects such as spina bifida $[28,29]$. However, very few studies addressed the consequences of a high MD supply during pregnancy and of the possible interactions with the macronutrient content in maternal diet. And yet, several authors point out a link between systematic food fortification and an increased frequency of cancer, neurological disorders and possibly insulin resistance [30-32]. This raises questions about the potential negative consequences of an exposure to high MD during fetal and early postnatal life (for review [24]). For instance, high levels of folic acid during fetal life were shown to exacerbate the deleterious effect of a postweaning high-fat diet on metabolic outcomes in mouse male offspring [33]. A high multivitamin intake during pregnancy alters the control of food intake [34] and increases the risk to develop obesity in Wistar male rats [35] by affecting DNA methylation in hypothalamus [36]. MDs can therefore have wide and various effects on outcomes ranging from fetal growth and development to the programming of metabolic disorders.

Imprinted genes have proven to be highly interesting for their role in developmental programming [6,37]. These genes are characterized by a parent-of-origindependent mono allelic expression which mostly relies on epigenetic marks established in male and female gametes at specific differentially methylated regions (DMRs) and imprinting control regions (ICRs). Imprinted genes are strongly involved in the regulation of fetal and postnatal growth [38] and in the postnatal control of energy homeostasis, including adipose tissue differentiation [39], glucose/insulin related metabolism [40] and appetite regulation (reviewed in [41]).

Observations on human cohorts have shown that maternal periconceptual undernutrition [42] or altered fetal growth [43,44] may affect imprinted gene methylation and that a supplementation with folic acid, alone [45] or combined with zinc and vitamins [46,47] influences this effect. Regarding the methylation status of IGF2 and H19 genes in particular, the observed effects are very small in magnitude and inconsistent between studies that differed for a multitude of confounding factors, such as the genetic heterogeneity of human populations, the age of the studied individu- als and the influence of multiple environmental factors (nutrition, stress). Studies on animal models make it possible to address the direct impact of specific nutrients without most of these confounding factors. However, studies conducted so far have shown variable and inconclusive results, depending mostly on the window of exposure and the nutritional changes [48-51]. The purpose of our study was to use a high MD supply in order to provide a nutritional challenge on the epigenetic machinery that requires methyl groups and address the lability/resistance of imprinted genes from the IGF system to this challenge.

We previously demonstrated in our model that MDs and proteins in maternal diet influence fetal and postnatal growth, insulin and leptin secretion [52] and neurodevelopment in the hippocampus [53]. Plasmatic homocysteine in male offspring at D21 was not affected by maternal diet. Postnatal growth and insulin secretion was impaired in offspring of protein restricted dams, whereas MD supplementation was associated with low plasma leptin at weaning. Male-only offspring from protein restricted-MD supplemented dams showed a reduced weight gain on control diet until the age of 23 weeks and remained $30 \%$ lighter than control males even after 4 weeks on western diet, despite a similar food intake, suggesting a difference in metabolic regulation or energy expenditure. We present here a unique and extensive study of the methylation profiles of DMRs, ICRs and promoter regions of several genes involving the IGF system in liver offspring.

\section{Materials \& methods}

Selection of MD doses in experimental diets

Four experimental diets were designed to address the combined effect of protein and MD content in maternal diet. Protein restricted diets contained $8 \%$ protein (vs 20\%) which is commonly used in many rodent models of nutritional programming ([12]. Protein restricted (R) or control (C) diets contained the recommended amounts of MDs and cofactors involved in methyl metabolism (methionine $[7.2 \mathrm{~g} /$ $\mathrm{kg}$ in the $\mathrm{C}$ diet] choline chloride $[1 \mathrm{~g} / \mathrm{kg}]$, folic acid [2 mg/kg], zinc [30 mg/kg], vitamin B12 [25 $\mu \mathrm{g} / \mathrm{kg}]$ ) that are required during pregnancy and lactation [54], except for methionine that was reduced in the $\mathrm{R}$ diet $(2.9 \mathrm{~g} / \mathrm{kg})$ because of global protein restriction. Two MD-supplemented diets [containing either 20\% (Csup) or 8\% (Rsup) protein] were designed to provide an increase in the total amount of both cofactors and MDs ( $\times 15$ for choline, $\times 40$ for vitamin B12, $\times 7$ for folic acid, $\times 6$ for zinc, $\times 1.6$ [Csup vs C] or $\times 4$ [Rsup vs R] for methionine and additional betaine $[15 \mathrm{~g} / \mathrm{kg}]$ ) (see Supplementary Table 1 for detailed composition of the diets). These amounts of MD nutrients were cho- 
sen according to previous studies showing an absence of toxicity together with an impact of the methylation status of specific genes [55,56]. They were also below the doses used in studies addressing the impact of a single supplementation with high doses of methionine [57] or folic acid [33].

\section{Animals \& diets}

The protocol for animal procedures was approved by the local ethics committee for animal experimentation (Comité Régional d'Ethique en Experimentation Animale Pays de Loire) under the licence number CEEA.2010.02, and described previously [52,53]. Briefly, virgin female Sprague Dawley rats, 7 weeks old, weighing 200-220 g, were fed the experimental diets for 21 to 28 days before mating, and throughout gestation and lactation (six females per group). At birth (D0), a subset of pups was sacrificed and litters were culled to eight pups per dam (four males and four females). At D21 (after overnight fasting), another subset of pups were sacrificed. A maximum of three (Csup) or two (C, R, Rsup) pups from the same litter, and a minimum of three (Csup) or four to five litters per group were considered. At both time points (D0, D21) pups were sacrificed by decapitation and liver was quickly removed, snap frozen in liquid nitrogen and stored at $-80^{\circ} \mathrm{C}$. Only male pups were analyzed in the present study.

\section{Real-time quantitative reverse transcriptase- polymerase chain reaction}

Total RNA was extracted from male offspring liver using Qiazol (Qiagen Sciences, MD, USA) according to the manufacturer's recommendations. Total RNA was quantified using the Nanovue spectrophotometer (GE Healthcare, France). RNA integrity was confirmed by agarose gel electrophoresis and, for a random set of samples, using the Agilent BioAnalyser 2100. cDNA synthesis and real-time polymerase chain reaction (PCR) were performed as previously described [53]. All samples were analyzed in duplicates and the cycle threshold $(\mathrm{Ct})$ values were averaged. Gene expression was normalized using the geometric mean of the expression of two reference genes $\beta$-actin $(A c t b)$ and beta 2 microglobulin $(B 2 m)$. The expression stability of these genes in liver was tested using the Genorm ${ }^{\circledR}$ Software [58]. When comparing the relative mRNA expression between the four groups at a given time point, the expression was calculated with the $2^{-}$ ${ }_{\Delta \Delta \mathrm{Ct}}$ method using the control group (C) as reference condition. When comparing the expression between D0 and D21 (Supplementary Figure 1), or between the three promoters of the $\operatorname{Ig} f 2$ gene (Figure 2B \& D) it was expressed as $2^{-\triangle C t} \times 10^{3}$. Expression changes were pre- sented as the ratio of the means between two groups. Primer sequences are given in Supplementary Table 2.

\section{Pyrosequencing DNA methylation analysis}

Genomic DNA was extracted from liver using the Nucleospin ${ }^{\circledR}$ Tissue kit (Macherey Nagel, GmbH and Co, France). Two micrograms were submitted to bisulfite modification using the Methyl Detector bisulfite modification kit (Active Motif Europe, Rixensart, Belgium) according to the manufacturer's instructions. Bisulfite converted DNA was amplified using the Pyromark $^{\circledR}$ PCR kit (Qiagen Sciences) and pyrosequencing was performed using the Pyromark ${ }^{\circledR}$ Q24 instrument (Qiagen Sciences) following the manufacturer's instructions. PCR and pyrosequencing primers were designed using the Pyromark ${ }^{\circledR}$ Assay Design software (Qiagen Sciences). Primer sequences are given in Supplementary Table 3.

\section{Statistical analyses}

Data were analyzed using GraphPad Prism ${ }^{\circledR} 5$ (GraphPad software Inc., CA, USA). Gene expression results ( $\mathrm{n}=8$ per group) were analyzed using two-way ANOVA followed by Bonferroni post hoc comparisons when appropriate, in order to evaluate the impact of protein restriction and MD supplementation. Pyrosequencing data ( $\mathrm{n}=4$ to 6 per group) were presented as absolute methylation levels of single $\mathrm{CpG}$ sites or the mean for several adjacent $\mathrm{CpG}$ sites (mentioned on the Figures 3-7). Data were analyzed used the nonparametric Kruskal-Wallis test followed by Dunn's multiple comparison post hoc test. Significant effects (p-values < 0.05 ) were indicated in Figures 1, 2, 6 \& 7).

\section{Results}

\section{Maternal diet affected the expression of} several imprinted genes at D0 and D21

The expression of the Igf2, H19, Plagll, Igf2r and Igf1 genes was assessed by quantitative RT-PCR on mRNA extracted from male liver at D0 and D21. At D0, the expression levels of Igf2, H19 and Plagll were significantly reduced (0.74, 0.57 and 0.55 -fold, respectively) in the $\mathrm{R}$ group compared with the $\mathrm{C}$ group, but this effect was no longer observed when the diets were supplemented with MD (Csup vs Rsup) (Figure 1A). To the contrary, Igf2r was overexpressed (3.45-fold) in the $\mathrm{R}$ group compared with the $\mathrm{C}$ group, and this effect was also observed when both diets were supplemented with MD. The IgfI expression did not vary either between the $\mathrm{R}$ and $\mathrm{C}$ groups, or between the Rsup and Csup groups.

The expression levels of Igf2, H19 and Plagl1 were strongly reduced at D21 compared with D0 (about 


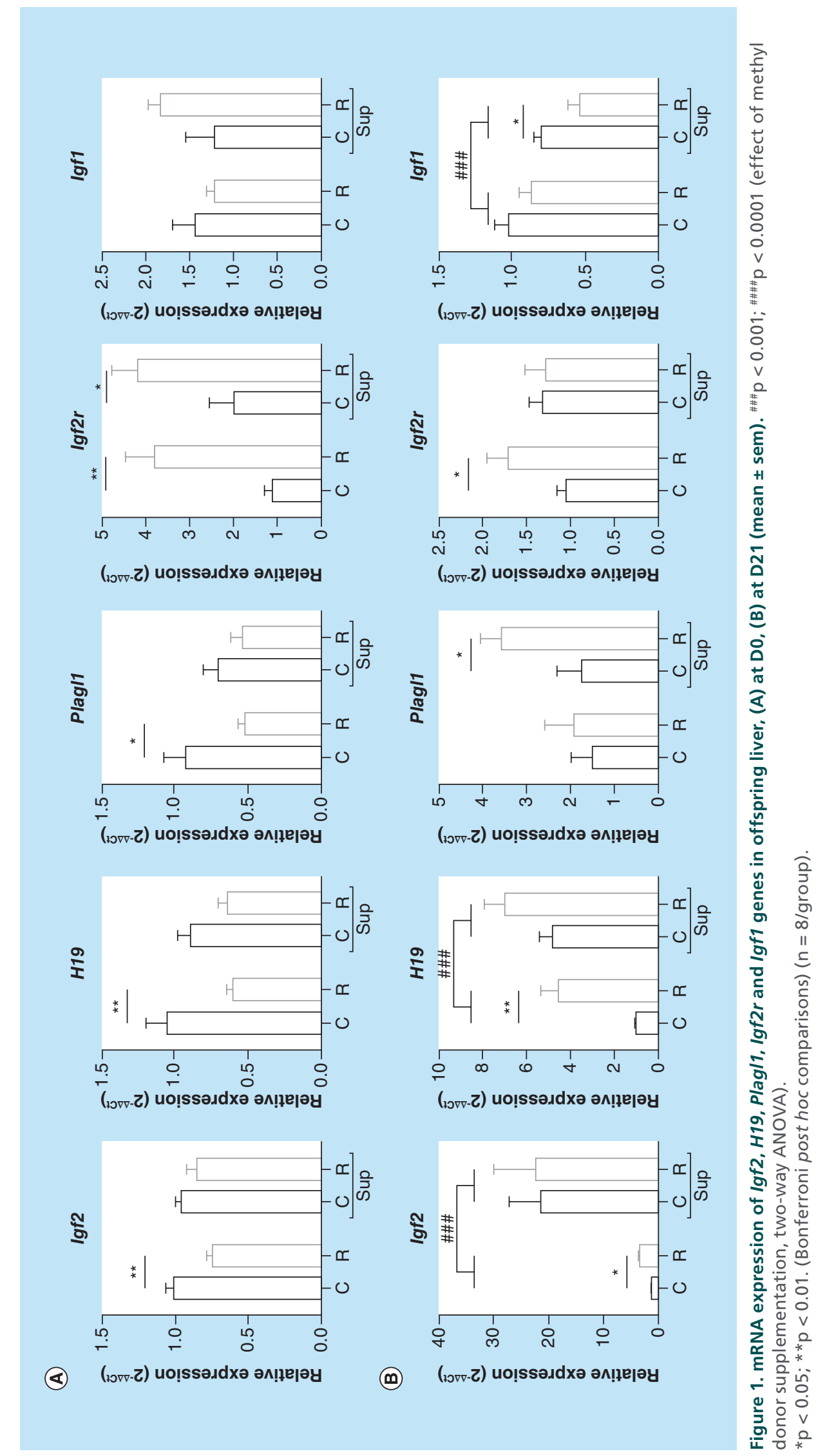


(A)

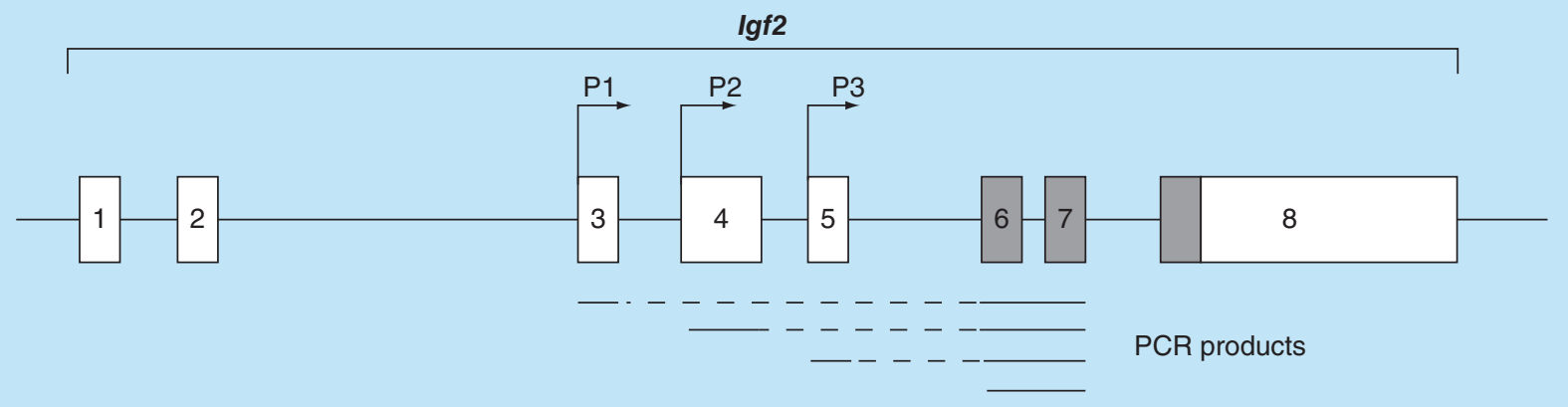

(B)

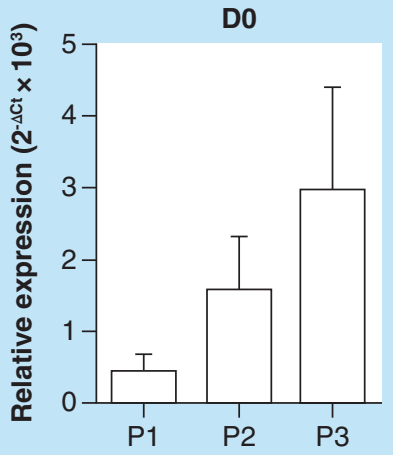

(D)

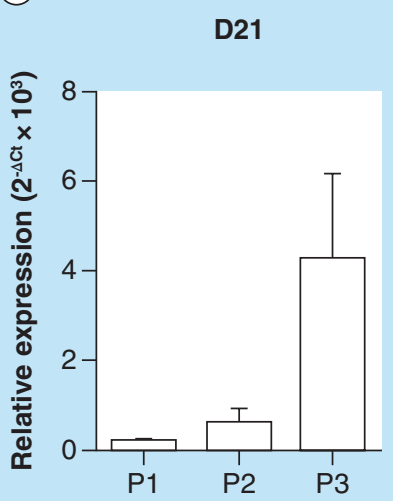

(C)

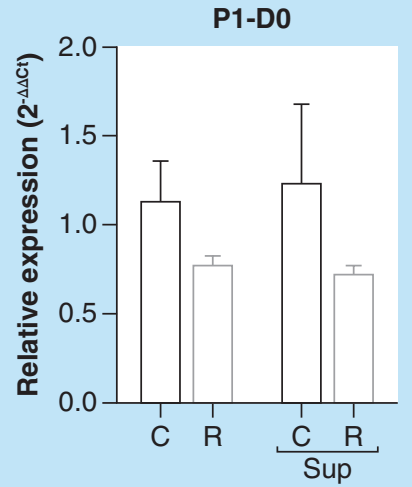

(E)
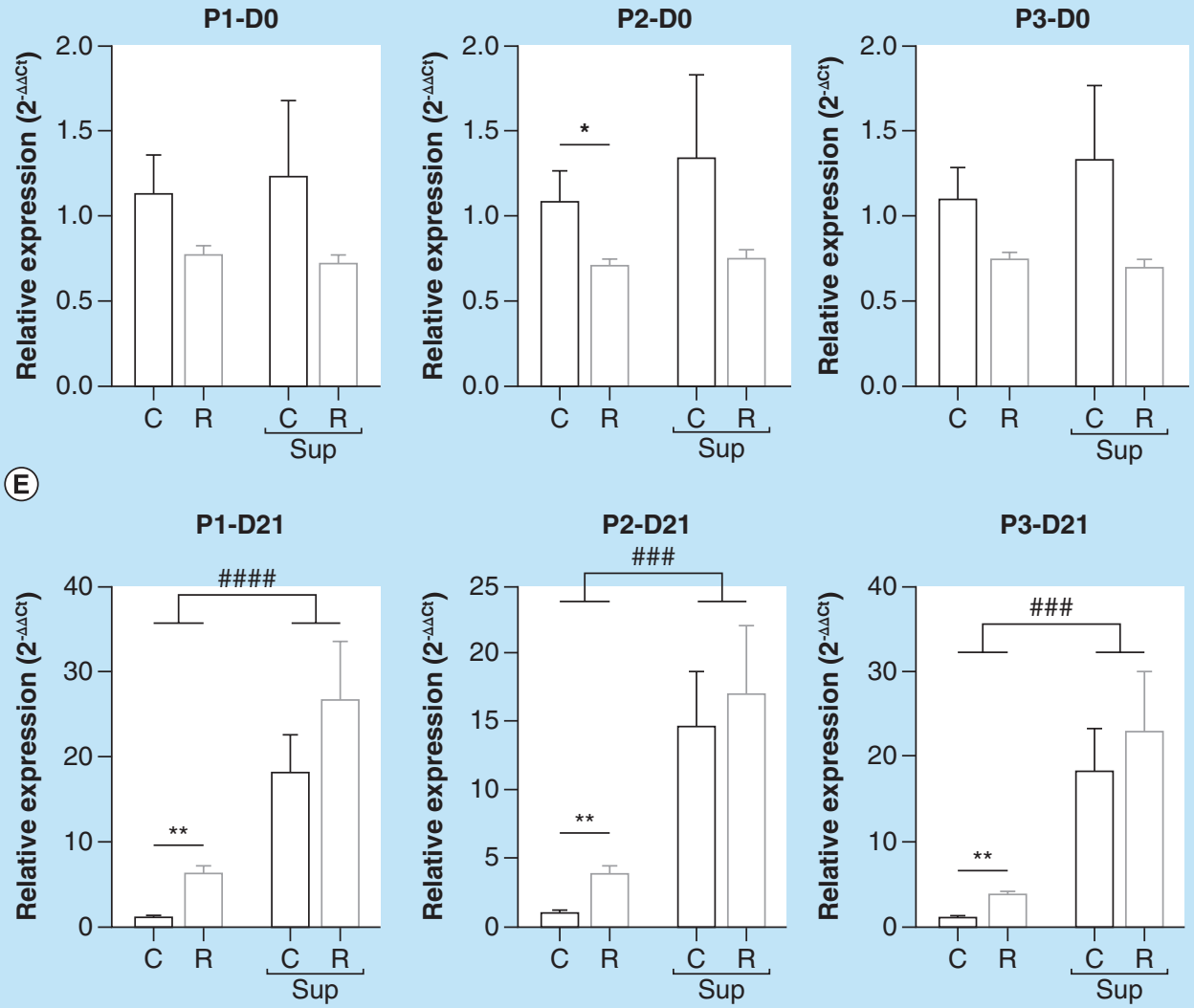

P3-D21

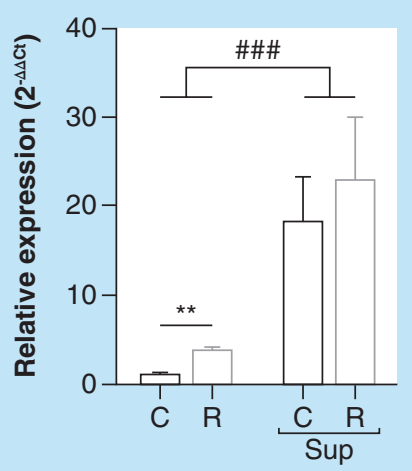

Figure 2. mRNA expression of Igf2-specific transcripts expressed from promoters P1, P2 and P3 in offspring liver. (A) genomic structure of the Igf2 gene. Noncoding exons are represented by open boxes and coding exons by filled boxes. The position of the P1, $\mathrm{P} 2$ and P3 promoters are indicated by arrows above the exons. Polymerase chain reaction products used to quantify the promoterspecific or the total Igf2 transcripts are presented below the gene structure. (B \& D) Relative expression of the P1, P2 and P3 specific transcripts in the C group at D0 (B) and D21 (D). (C \& E) Relative expression of the P1, P2 and P3 specific transcripts in the four experimental groups at D0 (C) and D21 (D) at D21. Data are expressed as mean \pm SEM ( $n=8 /$ group).

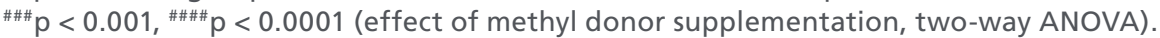

$* \mathrm{p}<0.05, * * \mathrm{p}<0.01$ (Bonferroni post hoc comparisons).

1000 -fold for Igf2 and H19) and, to the contrary, was higher for Igf1 at D21 (Supplementary Figure 1). At D21, the two-way ANOVA revealed a strong effect of high-MD on the expression of Igf2, H19 and IgfI (Figure 1B). Igf2 and $H 19$ were overexpressed in the $\mathrm{R}$ group compared with the $\mathrm{C}$ group (3.17- to $4.52-$ fold, respectively) and strongly overexpressed in the
Rsup and Csup groups (4.75- to 6.90-fold for H19 and 19.82- to 20.76-fold for Igf2). Plagl1 was slightly overexpressed in the Rsup group compared with Csup and $\operatorname{Igf} 2 r$ was overexpressed in the R group compared with C. The IgfI gene expression was influenced by the protein and MD content in maternal diet (twoway ANOVA). Whereas its expression was not dif- 
(A)

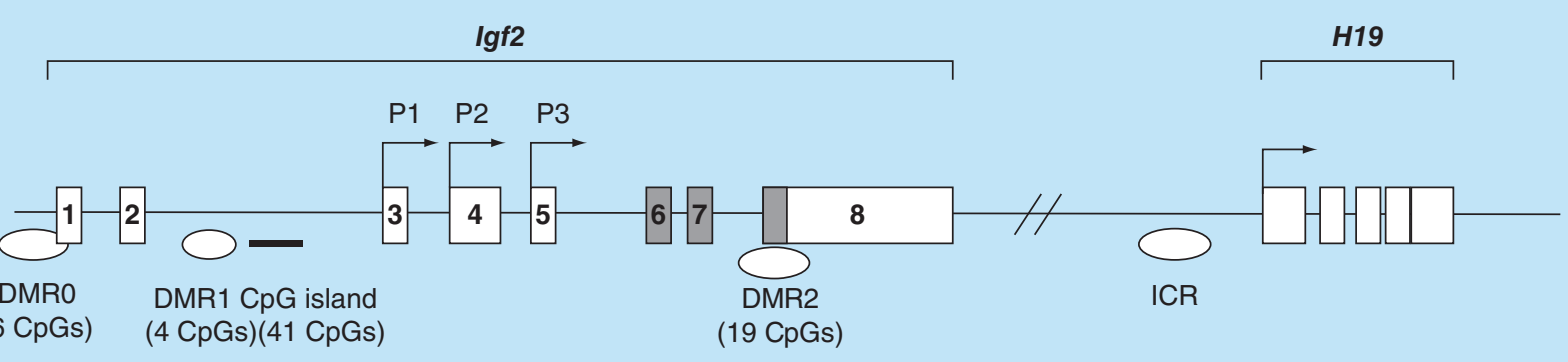

(B)

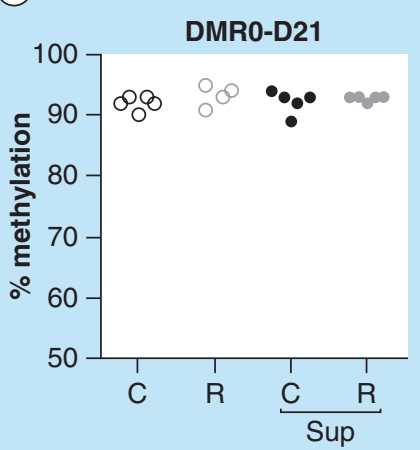

(C)

(D) CpG island-Do
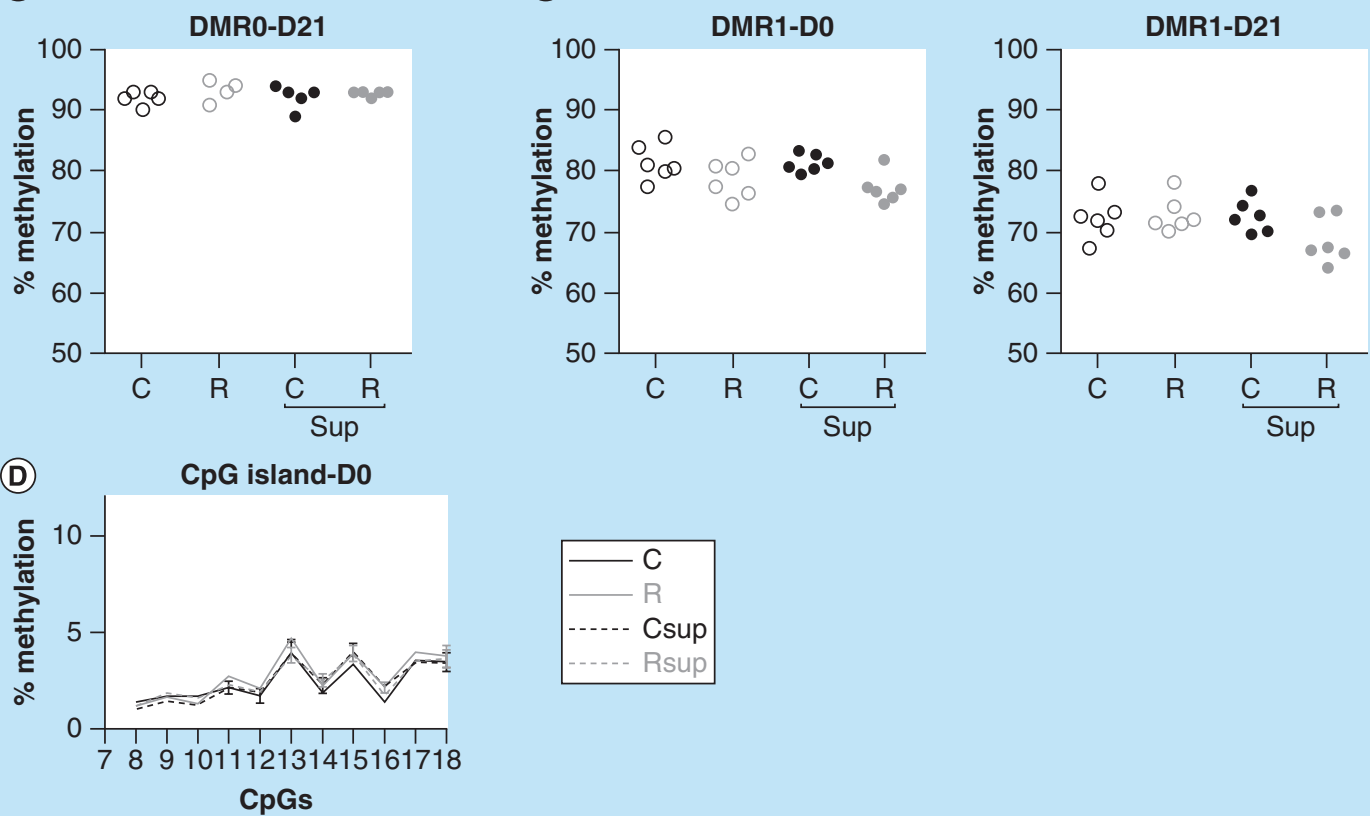

CpG island-D21

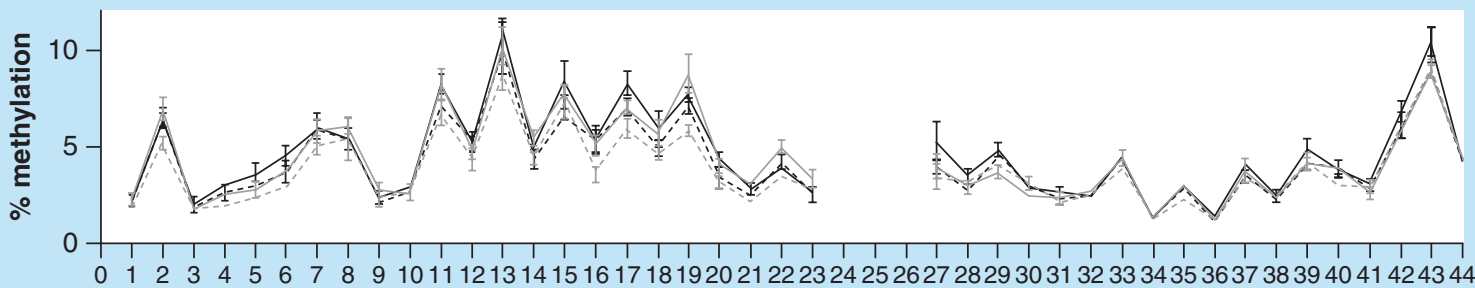

$0 \begin{array}{llllllllllll}1 & 2 & 3 & 4 & 5 & 6 & 7 & 8 & 9 & 1011121314151617181920212223242526272829303132 & 333435363738394041424344\end{array}$

(E)

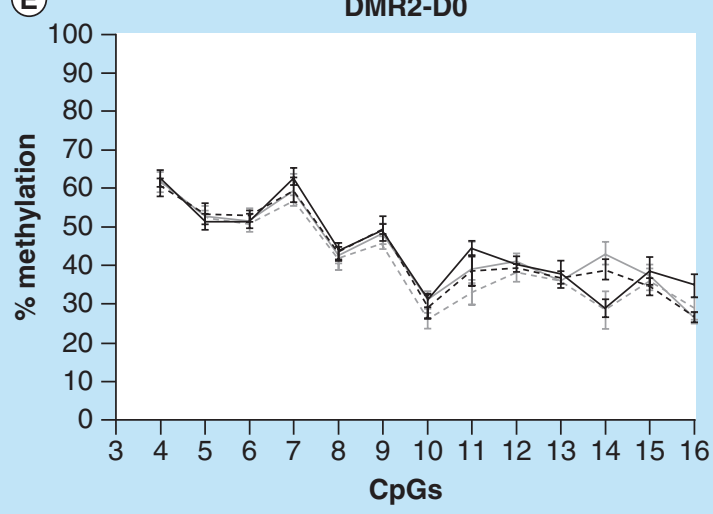

CpGs

DMR2-D21

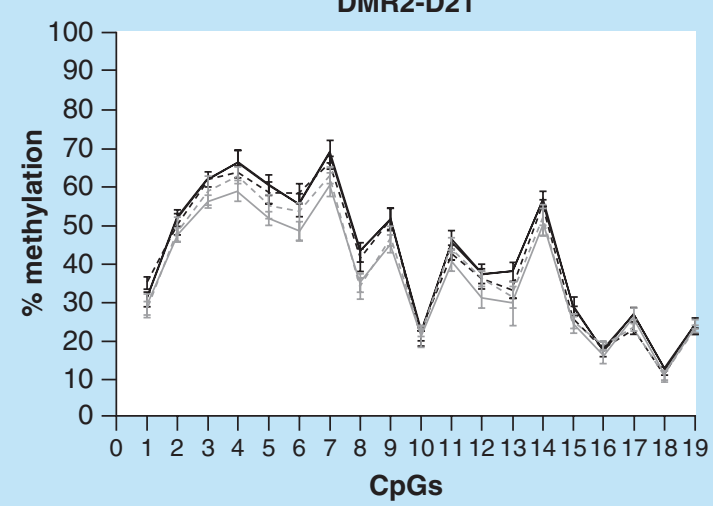


Figure 3. DNA methylation in offspring liver at lgf2 differentially methylated regions (see facing page).

(A) Genomic structure of the Igf2 / H19 locus. Non-coding exons are represented by open boxes and coding exons by filled boxes. The position of the P1, P2 and P3 promoters are indicated by arrows. The positions of the different differentially methylated regions (DMRs), the intron 2 CpG islands and the imprinted control regions are indicated below the gene structure. (B \& C) Methylation level of the DMR0 at D21 ( $n=4-5 /$ group), and DMR1 at D0 ( $n=6 /$ group) and D21 ( $n=6 /$ group). Each dot represents the average (mean) methylation level of six (DMR0) or four (DMR1) CpG sites for one specific DNA sample. (D \& E) Methylation level of individual CpG sites from the Igf2

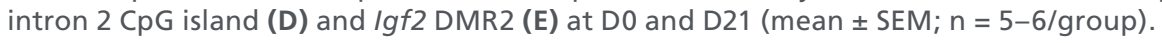

ferent between $\mathrm{C}$ and $\mathrm{R}$, it was significantly lower in the Rsup group compared with Csup, although the two-way ANOVA did not reveal any significant interaction. Since $I g f 2$ was overexpressed and $I g f 1$ was underexpressed in the high-MD groups, we tested whether their expression levels were correlated at D21. There was a significant inverse correlation $(r=-0.50$, $\mathrm{p}=0.0025)$ between the expression levels of the two genes (data not shown).

\section{Maternal diet influenced the expression level of all Igf2 promoters in liver}

Since the $\operatorname{Ig} f 2$ gene is expressed from a set of alternative promoters [59] (Figure 2A), we tested whether the observed differences in the expression level at D21 were promoter specific or not. Three reference transcripts of the rat $I g f 2$ gene are present in the Nucleotide database [60] and the three promoter regions of these transcripts were similar to $\mathrm{P} 1, \mathrm{P} 2$ and $\mathrm{P} 3$ promoters in mouse [59]. Igf2 was expressed predominantly from P3 at both D0 and D21, in all experimental groups. The proportion of transcripts expressed from P1 and P2 promoters at D0 was about 10 and 30\%, respectively (Figure $2 \mathrm{~B}$ ), and this proportion fell to 4 and $12 \%$ at D21 (Figure 2D). This relative proportion, shown for the $C$ group on Figure $2 B$ \& $D$ was similar in the other groups. However, at D0, when comparing separately the expression of each transcript among the four groups, only the P2-specific transcript was significantly under expressed in the R group compared with the $\mathrm{C}$ group (Figure $2 \mathrm{C}$ ). At D21, specific transcripts from all three promoters were overexpressed about threefold in the R group and between 15- and 30-fold in the Csup and Rsup groups compared with the $\mathrm{C}$ group (Figure 2E).

\section{Igf2 DMRs displayed variable methylation} levels that were not influenced by maternal nutrition.

The Igf2 DMR0 was identified by sequence similarity with the mouse genomic sequence. This region corresponds to the promoter region of the P0 placenta specific transcript and is known to have a parental specific methylation exclusively in placenta [61]. In liver at D21, six CpG sites from DMR0 were heavily methylated $(92.6 \% \pm 1.4)$ (Figure $3 \mathrm{~B}$ ) in all samples from the four experimental groups, which is consistent with the absence of expression of the P0 transcript (data not shown).

The intron 2 of the Igf2 gene contains the DMR1 (Figure 3A), which is conserved with mouse DMR1 [62] but is less GC-rich in the rat. This region is immediately followed by a $\mathrm{CpG}$ island, known to contain a muscle-specific repressor element involved in the regulation of growth [63]. Four CpG sites from DMR1 were highly methylated in liver at D0 and D21, with a slight decrease between D0 $(79.8 \% \pm 3.0)$ and D21 $(71.6 \% \pm 3.5)$ (Figure $3 \mathrm{C})$. To the contrary, the adjacent $\mathrm{CpG}$ island (Figure 4D) was hypomethylated at both D0 (16 CpG sites assessed, ranging from 0.5 to $5 \%$ ) and D21 (41 CpG sites, ranging from 1 to $10 \%$ ) (Figure 3D). There was no significant difference in the methylation level of these two regions between the four experimental groups.

$\operatorname{Igf2} \mathrm{DMR} 2$ is situated at the 3 'end of the $\operatorname{Igf} 2$ gene and overlaps the start of the last exon (Figure $3 \mathrm{~A}$ ). This region is known to be methylated on the expressed paternal allele in mouse fetus [64]. The methylation level of this region in rat liver was rather heterogeneous from one $\mathrm{CpG}$ site to another, with methylation levels ranging from 30 to $65 \%$ at D0 and from 15 to $70 \%$ at D21 (Figure 3E) but there was no significant difference between groups.

H19 DMRs showed a typical imprinted gene methylation status which was not influenced by maternal diet.

The GC-rich imprinted control region (ICR) situated from -4000 to -1000 relative to the $H 19$ transcription starting site (Figure 4A) is characterized by a paternal allele specific methylation. This region, strongly conserved among mammals, contains four binding sites for the vertebrate enhancer blocking factor CTCF and is essential for the control of imprint of $I g f 2$ and $H 19$ [65]. DNA methylation was measured for 15 (D0) to 22 (D21) CpG sites from the first part of the ICR (containing the first two CTCF-binding sites) and for 6 (D0) and 25 (D21) CpG sites from the second part of the ICR (containing the last two CTCF-binding sites). The methylation levels varied from 30 to $60 \%$ from one $\mathrm{CpG}$ to another but the methylation profiles throughout the two regions were strongly conserved from D0 to D21 and between the four experimental groups (Figure 4B \& 4C). 
(A)

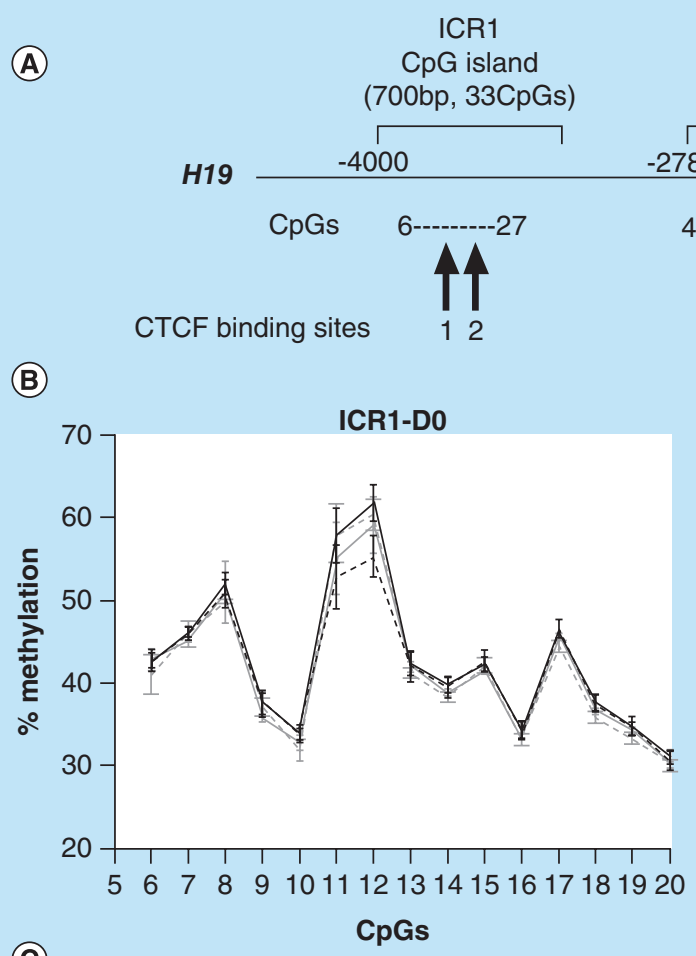

ICR2

CpG island

Promoter

(1400bp, 75CpGs)

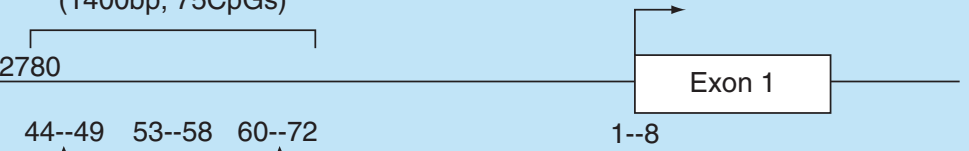

(B)
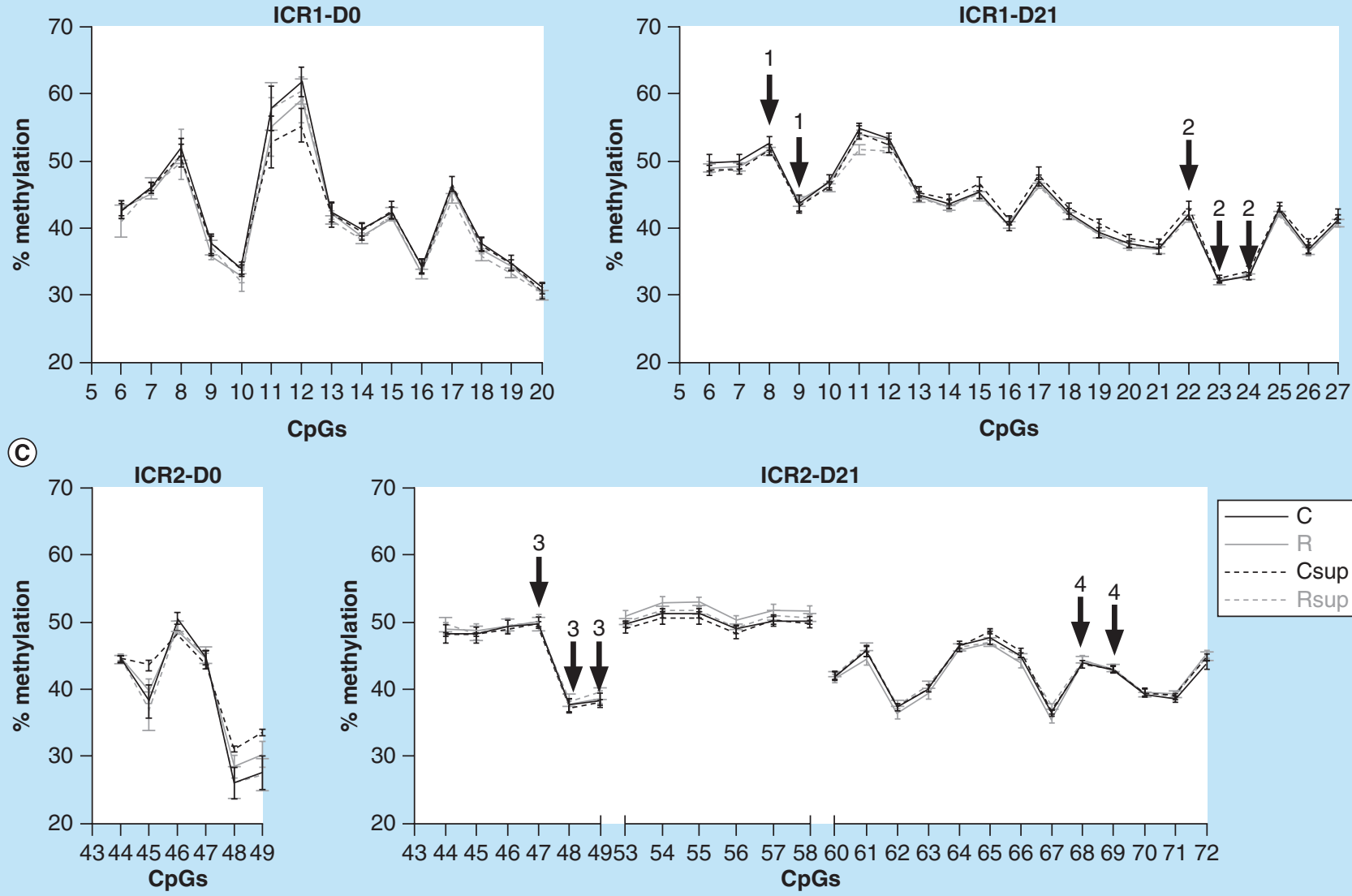

ICR2-D21

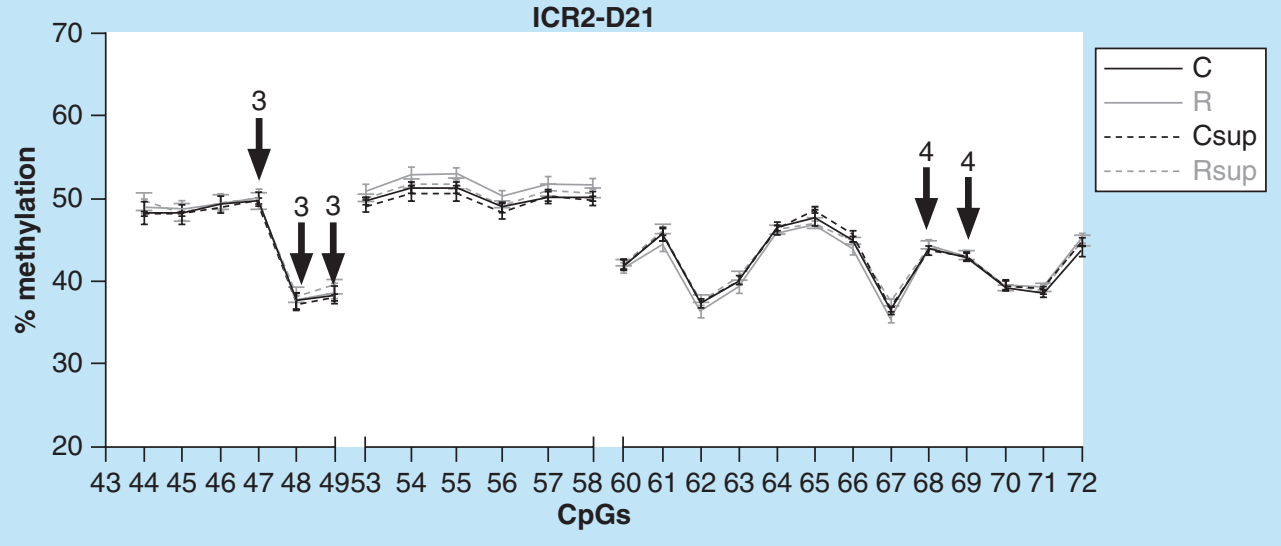

(D)
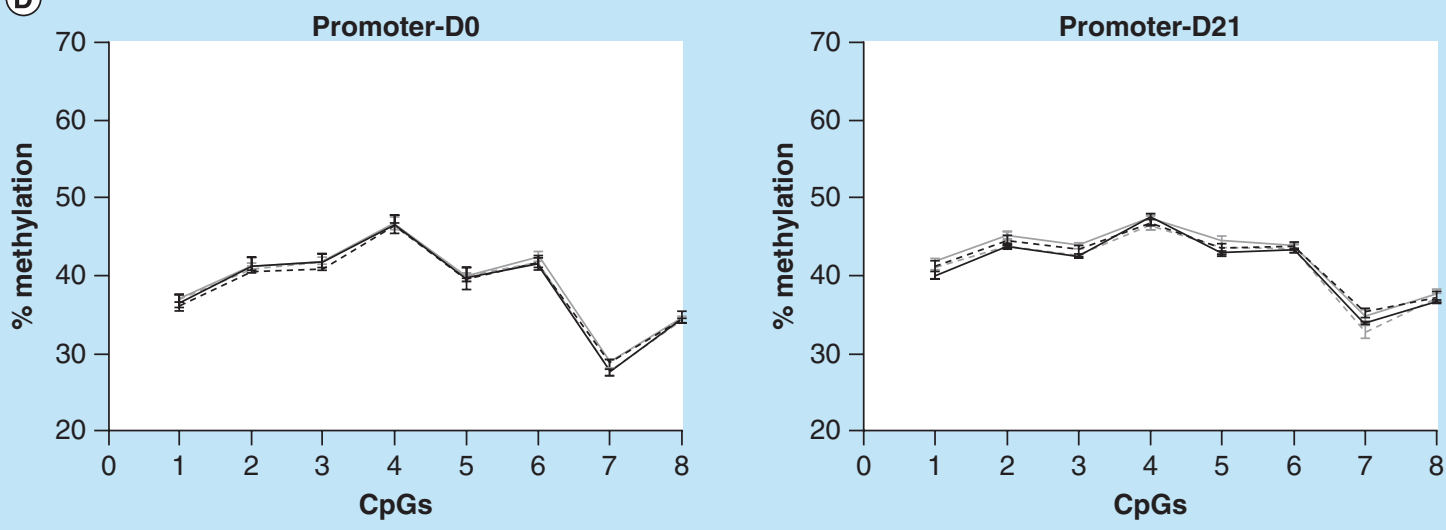

Figure 4. DNA methylation in offspring liver at $H 19$ imprinting control region. (A) Genomic structure of the $H 19$ upstream region. The position of the two CpG islands corresponding to the two parts of the imprinted control region (ICR) are indicated above the line. The CPG sites analyzed in this study are indicated below the line, as well as the position of the CTCF binding sites. (B, C \& D) Methylation levels of individual CpG sites from the ICR1 (B), ICR2 (C) and H19 promoter (D) at D0 and D21. The CpG sites embedded in the CTCF binding sites 1 to 4 are indicated by arrows above the curves (mean \pm SEM) ( $n=6 /$ group).

CTCF: CCCTC-binding factor . 
(A)

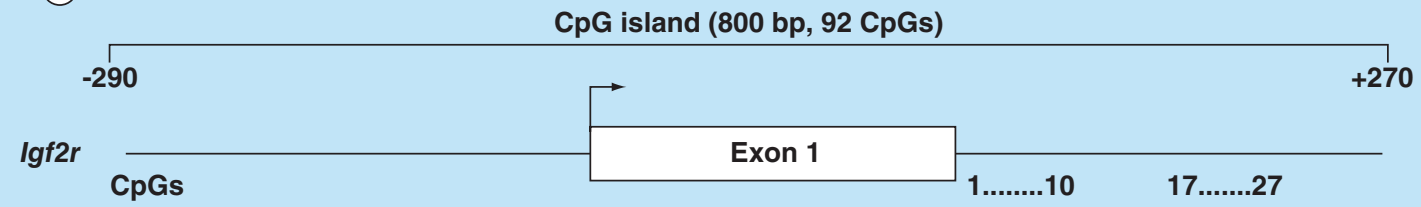

(B)
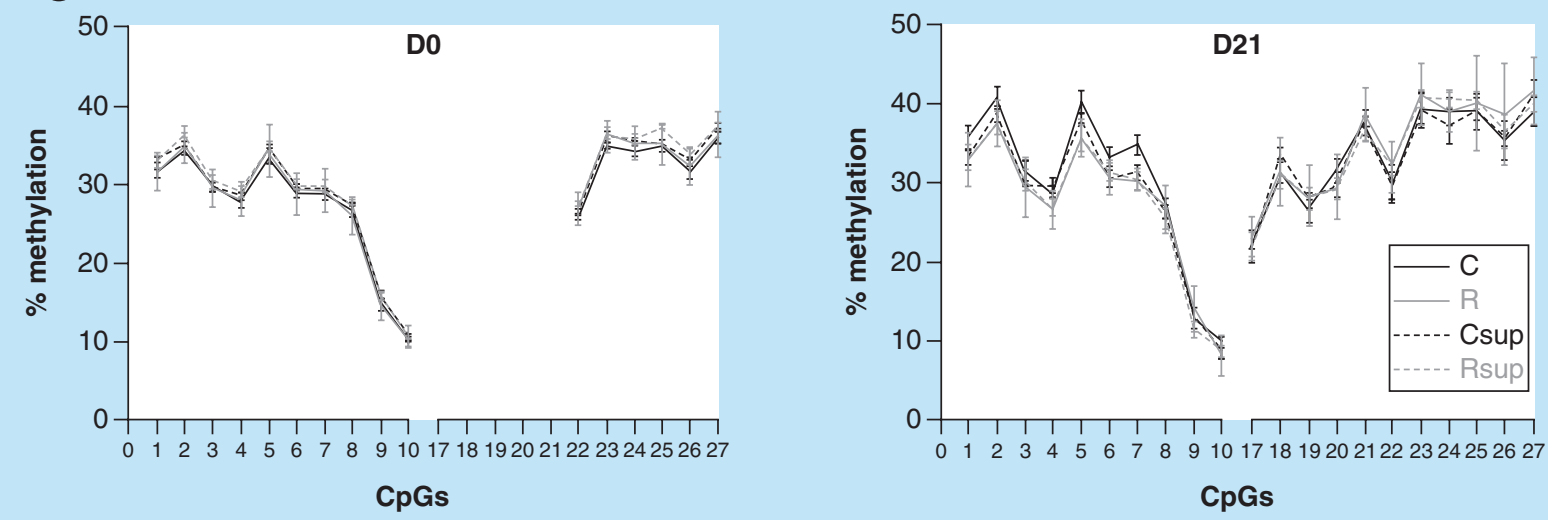

Figure 5. DNA methylation level in offspring liver of the CpG island covering the promoter, exon 1 and part of intron 2 of the Igf2r gene. (A) Position of the CpG island and of the CpG sites analyzed in this study. (B) Methylation level of individual CpG sites at D0 and D21 (mean \pm SEM) ( $n=6 /$ group)

The methylation level of eight CpG sites in the promoter region of $H 19$ was around $40 \%$ at both times with no difference between groups (Figure 4D).

\section{A CpG island spanning the 5'end of the Igf2r} gene was not influenced by maternal diet A large $\mathrm{CpG}$ island encompasses the promoter region, exon 1 and the beginning of the intron 1 of the $\operatorname{Igf} 2 r$ gene (Figure 5A). Because of the high density of CpG sites in the promoter region, it was impossible to design pyrosequencing assays. Methylation level was measured for $21 \mathrm{CpG}$ sites immediately downstream exon 1 . The methylation levels varied from 10 to $40 \%$ at D0 and D21 and were similar between the four experimental groups (Figure 5B).

\section{The Plag/1 promoter methylation was influenced by maternal diet}

We analyzed the methylation level of $21 \mathrm{CpG}$ sites from a large $\mathrm{CpG}$ island encompassing the promoter, exon1 and start of intron1 of the Plagl1 gene (Figure 6A). This region is conserved with mouse and human and corresponds to a DMR common to the PLAGLI and HYMAI imprinted genes [66,67]. Thirteen CpG sites from the promoter region were about $40 \%$ methylated at D0 and between 40 and $50 \%$ at D21 (Figure 6B). At both times, the methylation level was higher in the control group. The averaged methylation level of the CpGs 14-20 was significantly lower in the Csup group compared with the $\mathrm{C}$ group at D0 (-7.1\%) and in the $\mathrm{R}$ group compared with the $\mathrm{C}$ group at $\mathrm{D} 21$ (-7.05\%). To the contrary, the methylation levels of CpG 53-60 were similar between the four experimental groups.

\section{A growth hormone response element in Igf1} intron 2 was hypermethylated in response to maternal protein restriction

Unlike Igf2, H19, Igf2r and Plagl1 genes, the IgfI gene is not imprinted. However, its expression was shown to be associated with the methylation of several regulatory regions including growth hormone responsive elements (GHREs) and its two promoter regions P1 and P2 [47,68] (Figure 7A). Three CpG sites in the GHRE situated $72 \mathrm{~kb}$ upstream the Igfl gene were highly methylated at D0 $(84.1 \% \pm 1.4$ on average $)$ and at D21 $(88.0 \% \pm 3.9$ on average), and there was very little variability between samples and between the three CpG sites (Figure 7B). Three $\mathrm{CpG}$ sites in the P1 promoter were on average 35\% methylated (35.7 \pm 2.6) at D0 in all groups but their methylation level fell to less than $10 \%(9.4 \pm 2.5)$ at D21 (Figure 7C). Five CpG sites in the P2 promoter fell from $12 \%$ methylation $(12.4 \pm 2.3)$ at D0 to $7 \%(7.7 \pm 2.5)$ on average at D21 (Figure 7D). For both promoters, there was no difference between groups. The CpG1 in the GHRE situated in intron 2 of the IgfI gene was highly methylated at D0 $(61.5 \% \pm 2.9$, on average in all groups $)$, and fell to $21.3 \% \pm 4.5$ at D21 in the C, Csup and 
(A)

\section{CpG island (920 bp, 95 CpGs)}

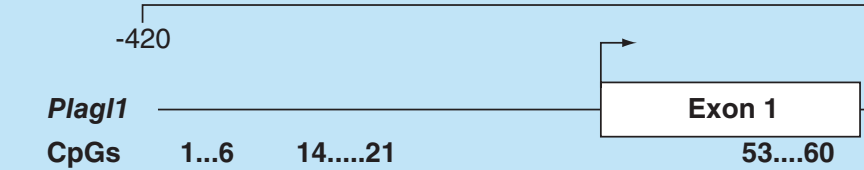

(B)

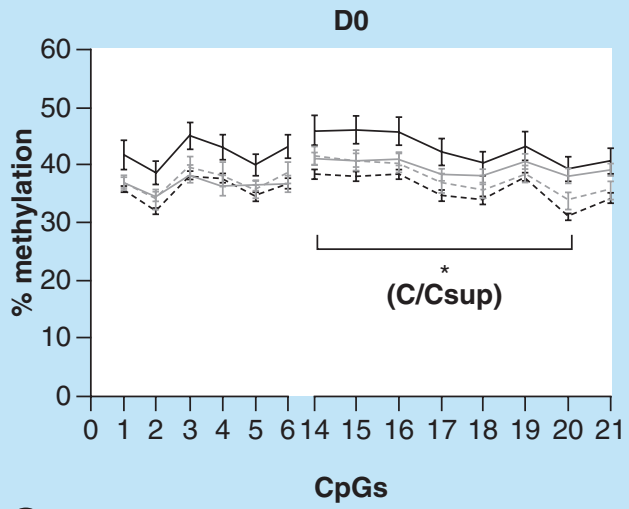

(C)

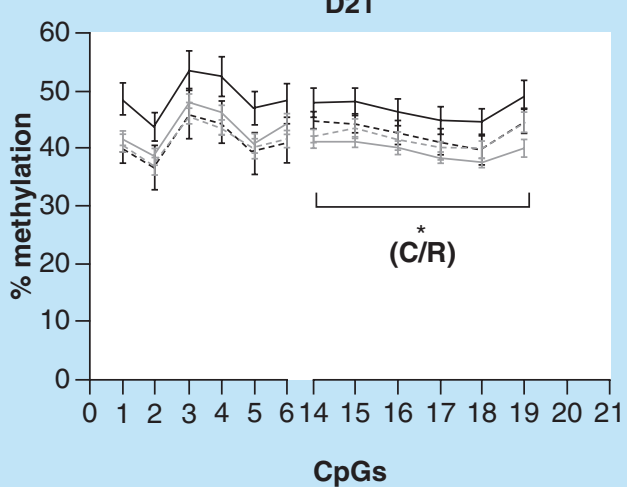

Do

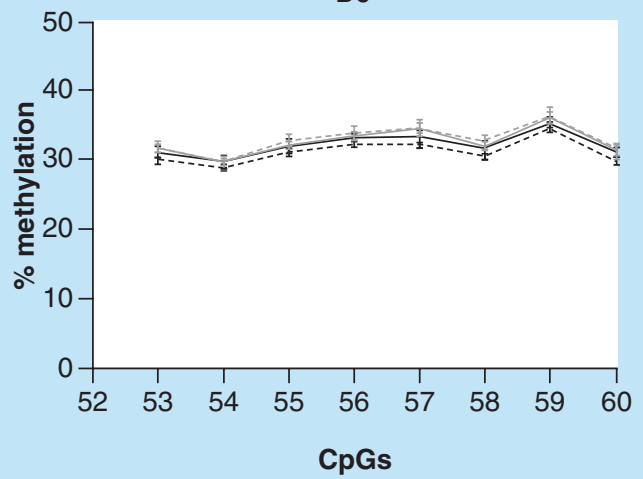

D21

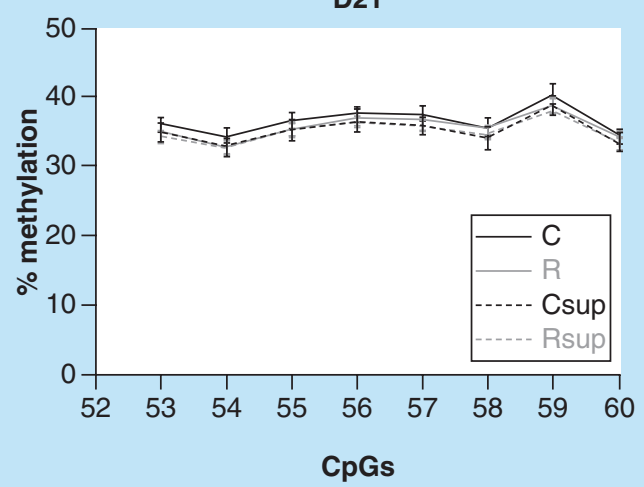

Figure 6. DNA methylation level in offspring liver of the CpG island covering the promoter, exon 1 and part of intron 2 of the Plagl1 gene. (A) Position of the CpG island and of the CpG sites analyzed in this study. (B \& C) Methylation level of individual CpG sites at D0 (B) and D21 (C).

${ }^{*} p<0.05$ (Dunn's post hoc test performed on the global mean of methylation levels for the considered CpG sites; mean \pm SEM; $n=6 /$ group).

Rsup groups, whereas it remained significantly more methylated $(35.4 \% \pm 4.2)$ in the R group (Figure 7E). The CpG2 from this GHRE was also hypermethylated in the $\mathrm{R}$ group compared with the three other groups.

\section{Discussion}

The present study was designed to test the impact of a protein restricted diet and a supplementation with MD nutrients during gestation and lactation on the expression level and the methylation status of genes involving the IGF system.

We decided to focus our attention on genes that are both involved in the control of fetal growth and in the regulation of energy homeostasis, including insulin- mediated metabolism [40] and adipose tissue development [39]. IGFI and IGFII are two major growth factors regulating fetal and postnatal growth [69]. Their action is driven by a very complex set of regulations, including the control of gene expression and translation efficiency, the modulation of bioavailability and receptor competition $[40,59,70]$. For instance, the regulation of $I g f 2$ is closely associated with the expression of the neighboring noncoding $H 19$ gene [71]. Both genes are under the control of transcription factors among which the zinc-finger transcription factor encoded by the Plagl1 gene [72] that acts through binding to a shared enhancer [67]. The IGFII-receptor, encoded by the Igf2 $r$ gene, acts as an antagonist of IGFII function by sequestering IGFII and 
(A)

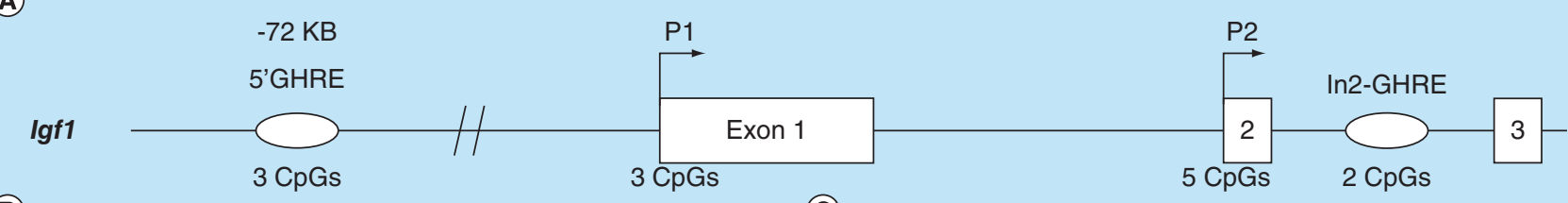

(B)
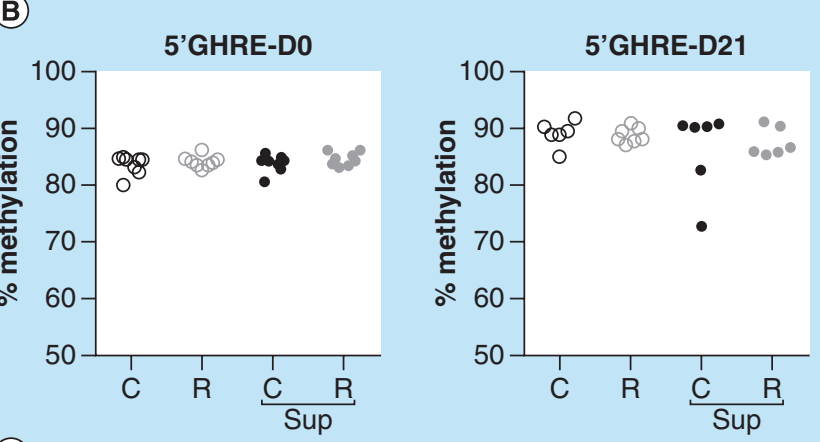

(C)

(D)
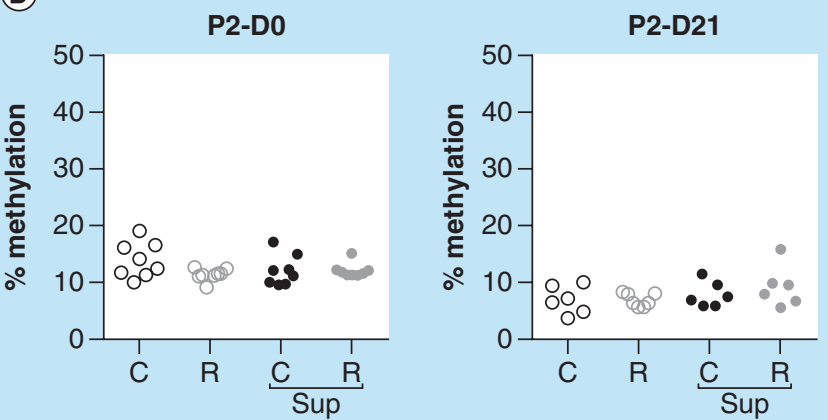

(E)
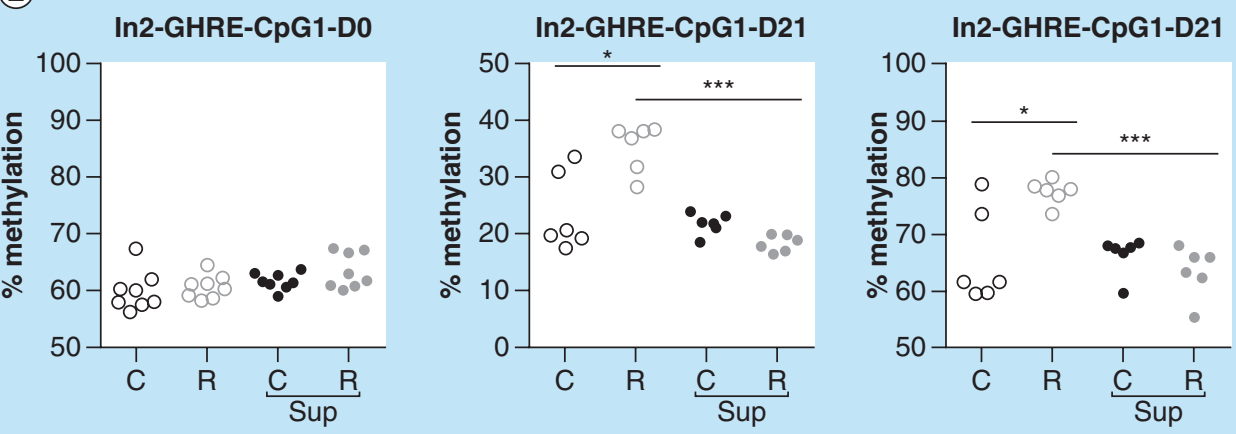

Figure 7. DNA methylation level in offspring liver of the growth hormone responsive elements and promoters of the lgf1 gene. (A) Position of the analyzed regions relative to the Igf1 gene, the exons are represented by open boxes, the promoters by arrows and the growth hormone responsive element (GHREs) by ovals. The number of CpG sites analyzed in this study is mentioned above the line. (B-D) Average methylation level of the 5'GHRE (B), Promoter P1 (C), Promoter P2 (D) at D0 and D21. Each dot represents the average (mean) methylation level of 3 (5'GHRE and P1) or 2 (P2) CpG sites for one specific DNA sample. (D) Methylation level of individual CpG sites in the intron2 (In2)-GHRE at D0 and D21.

${ }^{*} \mathrm{p}<0.05,{ }^{* *} \mathrm{p}<0.001$ (Dunn's post hoc test). ( $\left.\mathrm{n}=6 / \mathrm{group}\right)$.

targeting it for lysosomal degradation [73]. Therefore these two genes regulate the growth-promoting action of IGFII through two different ways, Plagl1 at the gene expression level and $\operatorname{Ig} f 2 r$ at the protein level.

The animal model used in this study was characterized previously [52]. Whereas the impact of maternal diet on birth weight and postnatal growth was rather similar between males and females, long-term impact on weight gain and especially when exposed to a hypercaloric diet, was observed in males only. This sex dimorphism in the susceptibility to respond to early nutrition is a known phenomenon evidenced both in human studies [74] and animal models [75]. Therefore, we decided to focus our study on male offspring. 
Protein restriction during gestation altered the expression of imprinted gene related to the synthesis and growth promoting action of IGFII \& high MD attenuated this effect.

The main effect observed at D0 in new born from protein restricted-low MD dams was a lower expression of the growth-promoting imprinted genes Igf2 and Plagl1 and an overexpression of the growth-restricting gene $\operatorname{Ig} f 2 r$ in liver. The observed changes in $\operatorname{Ig} f 2$ and $\operatorname{Ig} f 2 r$ mRNA expression levels may result in a reduced action of IGFII that could be an adaptive process to a reduced nutrient availability in the $\mathrm{R}$ group. Igf2 was under expressed in rat fetal liver after a maternal low protein diet during the preimplantation period only [76] whereas an overexpression was observed by Gong et al. [49] using a similar low-protein diet from the second day of gestation until birth, and no change of expression in a mouse model of maternal $50 \%$ caloric restriction from day 12.5 of pregnancy [77]. These discrepancies in results certainly reflect the importance of the window of exposure and highlight the major impact of the periconceptual period. In our study, the dams were fed the experimental diets for 3 weeks before mating which is closer to the situation encountered in human when women are taking prenatal folic acid or when they are exposed to supplemented foods. In the present study, dams had adapted their metabolism to the diet before entering pregnancy, and that may explain the fact that, although the expression of the growth-promoting genes was reduced in the $\mathrm{R}$ group, the pups did not suffer from intrauterine growth restriction (IUGR) [52]. It is indeed now established that maternal nutrition may have long-lasting consequences on offspring metabolic outcomes without any impact on birth weight, both in humans [78] and animal models $[12,79-80]$, and these consequences rely more on the time-window and nature of the nutritional insult than on growth restriction per se [80].

One interesting finding of our study was that high MD tended to attenuate the effect of protein restriction on the expression of Igf2, H19 and Plagll at D0, but not for the Igf2r gene. Plagl1 is known to regulate the expression of these two genes in liver [72], therefore it is possible that it mediates the expression changes we observed for Igf2 and H19. In addition, Plagl1 DMR methylation was reduced in presence of high MD at D0, although the link between its DMR methylation and its expression level has not yet been established. In humans, the methylation level of the Plagl1 DMR was shown to be associated with fetal and postnatal growth in healthy infants [81] and the expression of the gene was altered in IUGR placenta [67], strengthening our present results. Therefore, Plagl1 may represent a major target through which maternal diet influenced the expression level of several genes.
After D0, the switch from IGFII to IGFI for growth promotion was delayed by high-MD, possibly through epigenetic regulation of the In2GHRE

At D21, the Igf2 and H19 genes were strongly overexpressed in the high MD groups although their expression level was considerably reduced compared with D0. On the other hand, IgfI was under expressed at D21 in the high MD groups and the expression level of $I g f 2$ and $I g f 1$ were inversely correlated, suggesting that the normal transition of an Igf2 to IgfI postnatal growth induction was somehow delayed in the presence of high MD. Considering that postnatal growth is mostly driven by IgfI [82], this finding is consistent with the observation that postnatal growth was strongly impaired in the Rsup group [52], which certainly suffered from the double impact of protein restriction and low IGFI.

The Igfl gene is not an imprinted gene but it obviously plays a major role in fetal and postnatal growth [82] and its expression is tightly dependent on epigenetic regulation that controls specifically its activation by growth hormone $(\mathrm{GH})$ [47,83-84]. During postnatal life, circulating IGFI is mainly produced by the liver under the stimulation of GH but its ubiquitous production allows it to act through autocrine/ paracrine mechanisms in every tissue [85]. Postnatal increased hepatic IGFI production is correlated to changes in histone marks and DNA methylation at the In2-GHRE, a potent enhancer of IgfI transcription, conferring to this genomic region an open chromatin state $[68,86]$. These changes, including a decrease in DNA methylation, were shown to be less pronounced in a model of IUGR induced by uterine artery ligature [68]. In line with these data, the In2-GHRE DNA methylation decrease between D0 and D21 was lower in our R group, suggesting that the nutritional insult was sufficient to induce that, independently of an effect on fetal growth. Surprisingly, the MD supplementation normalized the DNA methylation level at D21, but this was not sufficient to restore expression levels similar to controls, possibly because the other epigenetic marks were not normalized or because of a state of GH resistance [87]. A better understanding of the current mechanism would require more investigations, in addition to the quantification of IGFI and GH plasma levels.

Our present study was not designed to test if the lower expression of IgfI was beneficial or not in the long term. However, the slowdown growth observed in Rsup rats was still noticeable at adulthood and conferred them a lower weight gain under western diet despite a similar food intake [52]. The role of the epigenetic regulation of $I g f 1$ in the protective effect against 
metabolic morbidities of a reduced postnatal growth after a nutritional restriction during fetal life was already suggested [88]. Our data reinforce this primary hypothesis and go further by suggesting that high-MD may enhance this effect, even though it remains to be determined whether this effect was due to the pre- or postnatal MD supplementation.

\section{The methylation profiles of most DMRs were not impacted by maternal nutrition}

We showed here that, despite significant changes in expression levels of several imprinted genes, only the Plagl1 DMR methylation level was influenced by maternal diet. Although studies on human cohorts have emphasized the effect of maternal nutrition on the methylation level of imprinted genes' DMRs [42,46,81,89-92], the demonstration of such effect on animal models still remains to be established. In agreement with previous results on a mice model of maternal protein restriction $[50,76]$, we found that, for the Igf2, $H 19$ and Igf2r genes, changes in the expression level are not related to alteration in the methylation pattern of the DMRs or promoters. This study was the first to address such a large number of $\mathrm{CpG}$ sites from the various DMRs of the $\operatorname{Ig} f 2$ gene and to reveal both a high diversity of methylation status from one $\mathrm{CpG}$ to another inside a DMR and a great homogeneity between individuals. These observations indicate a narrow and strong control of the methylation patterns that is resistant against potential environmental disturbances. The reason might be that an unaltered methylation pattern of imprinted genes is mandatory to ensure a normal feto-placental development [93] or that these genomic regions do not go through the demethylation wave that occurs just after fertilization [94].

A number of issues may be raised regarding our study, as it is the case for most animal models dealing with nutritional interventions. The protein restriction model results in the shortage of all amino acids which may influence a wide range of metabolic parameters. For instance, methionine is both involved in protein synthesis and in one-carbon metabolism [95]. Regarding MDs, we cannot conclude that the observed effects are not due to a specific nutrient rather that the combination of them. For instance, zinc is known to be involved in a wide range of biological functions, although its role during pregnancy remains elusive [96]. The purpose of our model was to increase the availability of methyl groups, whose main nutritional providers are folic acid, methionine and choline [97,98].

In addition, the choice to use a rat model and the pyrosequencing technology for DNA methylation quantification did not allow assessing allele-specific methylation, which would be potentially informative. However, the rat model of nutritional programming is widely used because it is more appropriate than mice for a number of physiological characteristics and pyrosequencing is recognized as one of the most accurate method for DNA methylation analyses.

\section{Future perspective}

We showed here that protein and MD content in maternal diet influenced the expression level of several imprinted genes in offspring liver at birth and weaning in the absence of modifications in the methylation status of imprinted DMRs. The Plagll gene was the only imprinted gene to show altered methylation level in response to maternal diet. Since this gene encodes a major transcription factor, further investigations are certainly required in order to address whether the Plagll gene constitute a specific target through which nutrients impact the expression level of a large number of genes. Additionally, we showed that MD supplementation was capable to restore the normal postnatal methylation decrease at the IgfIIn2-GHRE which was altered by protein restriction. Finally, we propose that the reduced postnatal $I g f I$ expression, induced by the combined effect of protein restriction and MD supplementation, may be the mechanism that minimizes the weight gain of our adult animals after slowing down their postnatal growth.

\section{Authors' contributions}

$\checkmark$ Amarger and $P$ Parnet designed and supervised the project. $\checkmark$ Amarger, F Giudicelli and A Pagniez performed the experiments. $V$ Amarger and F Giudicelli analyzed the data. $V$ Amarger and $\mathrm{P}$ Parnet wrote the manuscript. All authors read and approved the final manuscript.

\section{Acknowledgements}

The authors thank G Poupeau and I Gicquel for technical assistance.

\section{Financial \& competing interests disclosure}

This work was funded by INRA. F Giudicelli was supported by a grant from INRA and Région Pays de la Loire. The authors have no other relevant affiliations or financial involvement with any organization or entity with a financial interest in or financial conflict with the subject matter or materials discussed in the manuscript apart from those disclosed.

No writing assistance was utilized in the production of this manuscript.

\section{Ethical conduct of research}

The authors state that they have obtained appropriate institutional review board approval or have followed the principles 
outlined in the Declaration of Helsinki for all human or animal experimental investigations. In addition, for investigations involving human subjects, informed consent has been obtained from the participants involved.

\section{Open access}

This work is licensed under the Creative Commons Attribution 4.0 License. To view a copy of this license, visit http://creativecommons.org/licenses/by/4.0/

\section{Executive summary}

- Folic acid supplementation is highly recommended at the beginning of pregnancy and, associated with systematic food fortification and/or the use of multivitamins supplements may be responsible for high amounts of methyl donor (MD) micronutrients. The impact on the fetus and the interaction with macronutrient content in maternal diet are still poorly known.

- The IGF I and II are involved in fetal and postnatal growth and postnatal control of energy homeostasis. They may constitute major targets in early nutritional programming, possibly through an altered epigenetic regulation.

- The expression level of several imprinted genes from the IGF system was altered in the liver of offspring in response to the amount of protein and MDs in maternal diet during the gestation and lactation periods. A high MD content tended to reduce the effect of protein restriction during gestation.

- The methylation level of the $I g f 2, H 19$ and $I g f 2 r$ gene regulatory regions was remarkably stable in the liver of offspring. The Plag/1 gene promoter region was hypomethylated in response to MD supplementation or protein restriction at D0 and D21, respectively.

\section{References}

1 Godfrey KM, Barker DJ. Fetal nutrition and adult disease. Am. J. Clin. Nutr. 71(Suppl. 5), S1344-S1352 (2000).

2 Roseboom T, De Rooij S, Painter R. The Dutch famine and its long-term consequences for adult health. Early Hum. Dev. 82(8), 485-491 (2006).

3 Schulz LC. The Dutch Hunger Winter and the developmental origins of health and disease. Proc. Natl Acad. Sci. USA 107(39), 16757-16758 (2010).

4 Cetin I. Placental transport of amino acids in normal and growth-restricted pregnancies. Eur. J. Obstet. Gynecol. Reprod. Biol. 110(Suppl. 1), S50-S54 (2003).

5 Regnault TR, Friedman JE, Wilkening RB, Anthony RV, Hay WW Jr. Fetoplacental transport and utilization of amino acids in IUGR-a review. Placenta 26(Suppl. A), S52-S62 (2005).

6 Junien C, Nathanielsz P. Report on the IASO Stock Conference 2006: early and lifelong environmental epigenomic programming of metabolic syndrome, obesity and type II diabetes. Obes. Rev. 8(6), 487-502 (2007).

7 Langley-Evans SC. Fetal programming of cardiovascular function through exposure to maternal undernutrition. Proc. Nutr. Soc. 60(4), 505-513 (2001).

8 Zeisel SH. Epigenetic mechanisms for nutrition determinants of later health outcomes. Am. J. Clin. Nutr. 89(5), S1488S1493 (2009).

9 Vickers MH. Developmental programming and transgenerational transmission of obesity. Ann. Nutr. Metab. 64(Suppl. 1), 26-34 (2014).

10 Attig L, Gabory A, Junien C. Early nutrition and epigenetic programming: chasing shadows. Curr. Opin. Clin. Nutr. Metab. Care 13(3), 284-293 (2010).

11 Gueant JL, Elakoum R, Ziegler O et al. Nutritional models of foetal programming and nutrigenomic and epigenomic dysregulations of fatty acid metabolism in the liver and heart. Pflugers Arch. 466(5), 833-850 (2013).

12 Langley-Evans S, Swali A, Mcmullen S. Lessons from animal models: mechanisms of nutritional programming. In: 'Early Life Nutrition, Adult Health, and Development: Lessons from Changing Dietary Patterns, Famines, and Experimental Studies'. Vaiserman A, Lumey LH (Eds). Nova Science Publishers, NY, USA, 253-280 (2013).

13 Burdge GC, Hoile SP, Lillycrop KA. Epigenetics: are there implications for personalised nutrition? Curr. Opin. Clin. Nutr. Metab. Care 15(5), 442-447 (2012).

14 Altobelli G, Bogdarina IG, Stupka E, Clark AJ, LangleyEvans S. Genome-wide methylation and gene expression changes in newborn rats following maternal protein restriction and reversal by folic acid. PLoS ONE 8(12), e82989 (2013)

15 Lillycrop KA, Phillips ES, Jackson AA, Hanson MA, Burdge GC. Dietary protein restriction of pregnant rats induces and folic acid supplementation prevents epigenetic modification of hepatic gene expression in the offspring. J. Nutr. 135(6), 1382-1386 (2005).

16 Burdge GC, Slater-Jefferies J, Torrens C, Phillips ES, Hanson MA, Lillycrop KA. Dietary protein restriction of pregnant rats in the F0 generation induces altered methylation of hepatic gene promoters in the adult male offspring in the F1 and F2 generations. Br. J. Nutr. 97(3), 435-439 (2007).

17 Lillycrop KA, Phillips ES, Torrens C, Hanson MA, Jackson AA, Burdge GC. Feeding pregnant rats a protein-restricted diet persistently alters the methylation of specific cytosines in the hepatic PPAR alpha promoter of the offspring. Br. J. Nutr. 100 (2), 278-282 (2008).

18 Alexander BT. Epigenetic changes in gene expression: focus on "The liver X-receptor gene promoter is hypermethylated in a mouse model of prenatal protein restriction". Am. J. Physiol. Regul. Integr. Comp. Physiol. 298(2), R272-R274 (2010). 
19 Lillycrop KA, Rodford J, Garratt ES et al. Maternal protein restriction with or without folic acid supplementation during pregnancy alters the hepatic transcriptome in adult male rats. Br. J. Nutr. 103(12), 1711-1719 (2010).

20 Van Straten EM, Bloks VW, Huijkman NC et al. The liver $\mathrm{X}$-receptor gene promoter is hypermethylated in a mouse model of prenatal protein restriction. Am. J. Physiol. Regul. Integr. Comp. Physiol. 298(2), R275-R282 (2010).

21 Kulkarni A, Dangat K, Kale A, Sable P, Chavan-Gautam P, Joshi S. Effects of altered maternal folic acid, vitamin B12 and docosahexaenoic acid on placental global DNA methylation patterns in Wistar rats. PLoS ONE 6(3), e17706 (2011).

O’neill RJ, Vrana PB, Rosenfeld CS. Maternal methyl supplemented diets and effects on offspring health. Front. Genet. 5, 289 (2014).

23 Obeid R. The metabolic burden of methyl donor deficiency with focus on the betaine homocysteine methyltransferase pathway. Nutrients 5(9), 3481-3495 (2013).

24 Shorter KR, Felder MR, Vrana PB. Consequences of dietary methyl donor supplements: is more always better? Prog. Biophys. Mol. Biol. 118(1-2), 14-20 (2015).

25 Zeisel SH. Importance of methyl donors during reproduction. Am. J. Clin. Nutr. 89(2), S673-S677 (2009).

26 Chang $\mathrm{H}$, Zhang $\mathrm{T}$, Zhang $\mathrm{Z}$ et al. Tissue-specific distribution of aberrant DNA methylation associated with maternal low-folate status in human neural tube defects. $J$. Nutr. Biochem. 22(12), 1172-1177 (2011).

27 Gueant JL, Namour F, Gueant-Rodriguez RM, Daval JL. Folate and fetal programming: a play in epigenomics? Trends Endocrinol. Metab. 24(6), 279-289 (2013).

28 Atta CA, Fiest KM, Frolkis AD et al. Global birth prevalence of spina bifida by folic acid fortification status: a systematic review and meta-analysis. Am. J. Public Health 106(1), e24-e34 (2016).

29 Honein MA, Paulozzi LJ, Mathews TJ, Erickson JD, Wong LY. Impact of folic acid fortification of the US food supply on the occurrence of neural tube defects. JAMA 285(23), 2981-2986 (2001).

30 Smith AD, Kim YI, Refsum H. Is folic acid good for everyone? Am. J. Clin. Nutr. 87(3), 517-533 (2008).

31 Schaevitz LR, Berger-Sweeney JE. Gene-environment interactions and epigenetic pathways in autism: the importance of one-carbon metabolism. ILAR J. 53(3-4), 322-340 (2012).

32 Yajnik CS, Deshpande SS, Jackson AA et al. Vitamin B12 and folate concentrations during pregnancy and insulin resistance in the offspring: the Pune Maternal Nutrition Study. Diabetologia 51(1), 29-38 (2008).

33 Huang Y, He Y, Sun X, He Y, Li Y, Sun C. Maternal high folic acid supplement promotes glucose intolerance and insulin resistance in male mouse offspring fed a high-fat diet. Int. J. Mol. Sci. 15(4), 6298-6313 (2014).

34 Szeto IM, Aziz A, Das PJ et al. High multivitamin intake by Wistar rats during pregnancy results in increased food intake and components of the metabolic syndrome in male offspring. Am. J. Physiol. Regul. Integr. Comp. Physiol. 295(2), R575-R582 (2008).
35 Szeto IM, Das PJ, Aziz A, Anderson GH. Multivitamin supplementation of Wistar rats during pregnancy accelerates the development of obesity in offspring fed an obesogenic diet. Int. J. Obes. (Lond.) 33(3), 364-372 (2009).

36 Cho CE, Sanchez-Hernandez D, Reza-Lopez SA, Huot PS, Kim YI, Anderson GH. High folate gestational and post-weaning diets alter hypothalamic feeding pathways by DNA methylation in Wistar rat offspring. Epigenetics 8(7), 710-719 (2013).

37 Curley JP, Mashoodh R. Parent-of-origin and transgenerational germline influences on behavioral development: the interacting roles of mothers, fathers, and grandparents. Dev. Psychobiol. 52(4), 312-330 (2010).

Reik W, Constancia M, Fowden A et al. Regulation of supply and demand for maternal nutrients in mammals by imprinted genes. J. Physiol. 547(Pt 1), 35-44 (2003).

39 Jones BK, Levorse J, Tilghman SM. Deletion of a nucleasesensitive region between the Igf2 and H19 genes leads to Igf2 misregulation and increased adiposity. Hum. Mol. Genet. 10(8), 807-814 (2001).

40 Smith FM, Garfield AS, Ward A. Regulation of growth and metabolism by imprinted genes. Cytogenet. Genome Res. 113(1-4), 279-291 (2006).

41 Charalambous M, Da Rocha ST, Ferguson-Smith AC. Genomic imprinting, growth control and the allocation of nutritional resources: consequences for postnatal life. Curr. Opin. Endocrinol. Diabetes Obes. 14(1), 3-12 (2007).

42 Heijmans BT, Tobi EW, Stein AD et al. Persistent epigenetic differences associated with prenatal exposure to famine in humans. Proc. Natl Acad. Sci. USA 105(44), 17046-17049 (2008).

43 Tobi EW, Heijmans BT, Kremer D et al. DNA methylation of IGF2, GNASAS, INSIGF and LEP and being born small for gestational age. Epigenetics 6(2), 171-176 (2011).

44 Bouwland-Both MI, Van Mil NH, Stolk L et al. DNA methylation of IGF2DMR and H19 is associated with fetal and infant growth: the Generation R study. PLoS ONE 8(12), e81731 (2013).

45 Steegers-Theunissen RP, Obermann-Borst SA, Kremer D et al. Periconceptional maternal folic acid use of 400 microg per day is related to increased methylation of the IGF2 gene in the very young child. PLoS ONE 4(11), e7845 (2009).

46 Cooper WN, Khulan B, Owens S et al. DNA methylation profiling at imprinted loci after periconceptional micronutrient supplementation in humans: results of a pilot randomized controlled trial. FASEB J. 26(5), 1782-1790 (2012).

47 Ouni M, Belot MP, Castell AL, Fradin D, Bougneres P. The P2 promoter of the IGF1 gene is a major epigenetic locus for GH responsiveness. Pharmacogenomics J. 16(1), 102-106 (2016).

48 Claycombe KJ, Uthus EO, Roemmich JN, Johnson LK, Johnson WT. Prenatal low-protein and postnatal high-fat Diets induce rapid adipose tissue growth by Inducing Igf2 expression in Sprague Dawley rat offspring. J. Nutr. 143(10), 1533-1539 (2013). 
49 Gong L, Pan YX, Chen H. Gestational low protein diet in the rat mediates $\operatorname{Ig} f 2$ gene expression in male offspring via altered hepatic DNA methylation. Epigenetics 5(7), 619-626 (2010).

50 Ivanova E, Chen JH, Segonds-Pichon A, Ozanne SE, Kelsey G. DNA methylation at differentially methylated regions of imprinted genes are resistant to developmental programming by maternal nutrition. Epigenetics 7(10), 1200-1210 (2012).

51 Lan X, Cretney EC, Kropp J et al. Maternal diet during pregnancy induces gene expression and DNA methylation changes in fetal tissues in sheep. Front. Genet. 4, 49 (2013).

52 Giudicelli F, Brabant AL, Grit I, Parnet P, Amarger V. Excess of methyl donor in the perinatal period reduces postnatal leptin secretion in rat and interacts with the effect of protein content in diet. PLoS ONE 8(7), e68268 (2013).

53 Amarger V, Lecouillard A, Ancellet L et al. Protein content and methyl donors in maternal diet interact to influence the proliferation rate and cell fate of neural stem cells in rat hippocampus. Nutrients 6(10), 4200-4217 (2014).

54 Reeves PG. Components of the AIN-93 diets as improvements in the AIN-76A diet. J. Nutr. 127(Suppl. 5), S838-S841 (1997).

55 Waterland RA, Dolinoy DC, Lin JR, Smith CA, Shi X, Tahiliani KG. Maternal methyl supplements increase offspring DNA methylation at Axin Fused. Genesis 44(9), 401-406 (2006).

56 Wolff GL, Kodell RL, Moore SR, Cooney CA. Maternal epigenetics and methyl supplements affect agouti gene expression in Avy/a mice. FASEB J. 12(11), 949-957 (1998).

57 Finkelstein JD, Martin JJ. Methionine metabolism in mammals. Adaptation to methionine excess. J. Biol. Chem. 261(4), 1582-1587 (1986).

58 Vandesompele J, De Preter K, Pattyn F et al. Accurate normalization of real-time quantitative RT-PCR data by geometric averaging of multiple internal control genes. Genome Biol. 3(7), RESEARCH0034 (2002).

59 Monk D, Sanches R, Arnaud P et al. Imprinting of IGF2 P0 transcript and novel alternatively spliced INS-IGF2 isoforms show differences between mouse and human. Hum. Mol. Genet. 15(8), 1259-1269 (2006).

60 NCBI Nucleotide Database. www.ncbi.nlm.nih.gov/nucleotide

61 Moore T, Constancia M, Zubair M et al. Multiple imprinted sense and antisense transcripts, differential methylation and tandem repeats in a putative imprinting control region upstream of mouse Igf2. Proc. Natl Acad. Sci. USA 94(23), 12509-12514 (1997).

62 Eden S, Constancia M, Hashimshony T et al. An upstream repressor element plays a role in Igf2 imprinting. $E M B O J$. 20 (13), 3518-3525 (2001).

63 Markljung E, Jiang L, Jaffe JD et al. ZBED6, a novel transcription factor derived from a domesticated DNA transposon regulates IGF2 expression and muscle growth. PLoS Biol. 7(12), e1000256 (2009).

64 Murrell A, Heeson S, Bowden L et al. An intragenic methylated region in the imprinted $\operatorname{Ig} f 2$ gene augments transcription. Embo Rep. 2(12), 1101-1106 (2001).
65 Bell AC, Felsenfeld G. Methylation of a CTCF-dependent boundary controls imprinted expression of the Igf 2 gene. Nature 405(6785), 482-485 (2000).

66 Arima T, Drewell RA, Arney KL et al. A conserved imprinting control region at the HYMAI/ZAC domain is implicated in transient neonatal diabetes mellitus. Hum. Mol. Genet. 10(14), 1475-1483 (2001).

67 Iglesias-Platas I, Martin-Trujillo A, Petazzi P, GuillaumetAdkins A, Esteller M, Monk D. Altered expression of the imprinted transcription factor PLAGL1 deregulates a network of genes in the human IUGR placenta. Hum. Mol. Genet. 23(23), 6275-6285 (2014).

68 Fu Q, Mcknight RA, Callaway CW, Yu X, Lane RH, Majnik AV. Intrauterine growth restriction disrupts developmental epigenetics around distal growth hormone response elements on the rat hepatic IGF-1 gene. FASEB J. 29(4), 1176-1184 (2015).

69 Annunziata M, Granata R, Ghigo E. The IGF system. Acta Diabetol. 48(1), 1-9 (2011).

70 Hwa V, Oh Y, Rosenfeld RG. The insulin-like growth factorbinding protein (IGFBP) superfamily. Endocr. Rev. 20(6), 761-787 (1999).

71 Constancia M, Dean W, Lopes S, Moore T, Kelsey G, Reik W. Deletion of a silencer element in Igf2 results in loss of imprinting independent of H19. Nat. Genet. 26(2), 203-206 (2000).

72 Varrault A, Gueydan C, Delalbre A et al. Zac1 regulates an imprinted gene network critically involved in the control of embryonic growth. Dev. Cell 11(5), 711-722 (2006).

73 Ludwig T, Le Borgne R, Hoflack B. Roles for mannose-6phosphate receptors in lysosomal enzyme sorting, IGF-II binding and clathrin-coat assembly. Trends Cell Biol. 5(5), 202-206 (1995).

74 Stein AD, Rundle A, Wada N, Goldbohm RA, Lumey LH. Associations of gestational exposure to famine with energy balance and macronutrient density of the diet at age 58 years differ according to the reference population used. J. Nutr. 139(8), 1555-1561 (2009).

75 Palou M, Priego T, Sanchez J, Palou A, Pico C. Sexual dimorphism in the lasting effects of moderate caloric restriction during gestation on energy homeostasis in rats is related with fetal programming of insulin and leptin resistance. Nutr. Metab. (Lond.) 7, 69 (2010).

76 Kwong WY, Miller DJ, Ursell E et al. Imprinted gene expression in the rat embryo-fetal axis is altered in response to periconceptional maternal low protein diet. Reproduction 132(2), 265-277 (2006).

77 Radford EJ, Isganaitis E, Jimenez-Chillaron J et al. An unbiased assessment of the role of imprinted genes in an intergenerational model of developmental programming. PLoS Genet. 8(4), e1002605 (2012).

78 Stein AD, Zybert PA, Van De Bor M, Lumey LH. Intrauterine famine exposure and body proportions at birth: the Dutch Hunger Winter. Int. J. Epidemiol. 33(4), 831-836 (2004).

79 Langley-Evans SC, Gardner DS, Jackson AA. Association of disproportionate growth of fetal rats in late gestation with 
raised systolic blood pressure in later life. J. Reprod. Fertil. 106(2), 307-312 (1996).

Nusken KD, Schneider H, Plank C et al. Fetal programming of gene expression in growth-restricted rats depends on the cause of low birth weight. Endocrinology 152(4), 1327-1335 (2011).

81 Azzi S, Sas TC, Koudou Y et al. Degree of methylation of ZAC1 (PLAGL1) is associated with prenatal and post-natal growth in healthy infants of the EDEN mother child cohort. Epigenetics 9(3), 338-345 (2014).

82 Baker J, Liu JP, Robertson EJ, Efstratiadis A. Role of insulinlike growth factors in embryonic and postnatal growth. Cell 75(1), 73-82 (1993).

83 Ouni M, Gunes Y, Belot MP, Castell AL, Fradin D, Bougneres P. The IGF1 P2 promoter is an epigenetic QTL for circulating IGF1 and human growth. Clin. Epigenetics 7(1), 22 (2015).

84 Fu Q, Yu X, Callaway CW, Lane RH, Mcknight RA. Epigenetics: intrauterine growth retardation (IUGR) modifies the histone code along the rat hepatic IGF-1 gene. FASEB J. 23(8), 2438-2449 (2009).

85 Kaplan SA, Cohen P. The somatomedin hypothesis 2007: 50 years later. J. Clin. Endocrinol. Metab. 92(12), 4529-4535 (2007).

86 Chia DJ, Varco-Merth B, Rotwein P. Dispersed chromosomal Stat5b-binding elements mediate growth hormone-activated insulin-like growth factor-I gene transcription. J. Biol. Chem. 285(23), 17636-17647 (2010).

87 Fazeli PK, Klibanski A. Determinants of GH resistance in malnutrition. J. Endocrinol. 220 (3), R57-R65 (2014).

Tosh DN, Fu Q, Callaway CW et al. Epigenetics of programmed obesity: alteration in IUGR rat hepatic IGFI mRNA expression and histone structure in rapid vs. delayed postnatal catch-up growth. Am. J. Physiol. Gastrointest. Liver Physiol. 299(5), G1023-G1029 (2010).
89 Tobi EW, Lumey LH, Talens RP et al. DNA methylation differences after exposure to prenatal famine are common and timing- and sex-specific. Hum. Mol. Genet. 18(21), 4046-4053 (2009).

90 Haggarty P, Hoad G, Campbell DM, Horgan GW, Piyathilake C, Mcneill G. Folate in pregnancy and imprinted gene and repeat element methylation in the offspring. Am. J. Clin. Nutr. 97(1), 94-99 (2013).

91 Lee HS, Barraza-Villarreal A, Biessy C et al. Dietary supplementation with polyunsaturated fatty acid during pregnancy modulates DNA methylation at IGF2/H19 imprinted genes and growth of infants. Physiol. Genomics 46(23), 851-857 (2014).

92 Loke YJ, Galati JC, Morley R et al. Association of maternal and nutrient supply line factors with DNA methylation at the imprinted IGF2/H19 locus in multiple tissues of newborn twins. Epigenetics 8(10), 1069-1079 (2013).

93 Fauque P, Ripoche MA, Tost J et al. Modulation of imprinted gene network in placenta results in normal development of in vitro manipulated mouse embryos. Hum. Mol. Genet. 19(9), 1779-1790 (2010).

94 Paulsen M, Ferguson-Smith AC. DNA methylation in genomic imprinting, development, and disease. J. Pathol. 195(1), 97-110 (2001).

95 Rees WD, Wilson FA, Maloney CA. Sulfur amino acid metabolism in pregnancy: the impact of methionine in the maternal diet. J. Nutr. 136(Suppl. 6), S1701-S1705 (2006).

96 Donangelo CM, King JC. Maternal zinc intakes and homeostatic adjustments during pregnancy and lactation. Nutrients 4(7), 782-798 (2012).

97 Waterland RA. Assessing the effects of high methionine intake on DNA methylation. J. Nutr. 136(Suppl. 6), S1706-S1710 (2006).

98 Niculescu MD, Zeisel SH. Diet, methyl donors and DNA methylation: interactions between dietary folate, methionine and choline. J. Nutr. 132(Suppl. 8), S2333-S2335 (2002). 